\title{
A Real-Life Study: Intravitreal Aflibercept, Ranibizumab and Dexamethasone for Macular Edema Secondary to Branch Retinal Vein Occlusion
}

\author{
(1) Alper Halil Bayat, (1) Selim Bölükbasi, (1) Burak Erden, (1) Akin Cakir, (1) Seyma Gulcenur Ozturan, \\ (1) Mehmet Tayfur, (1) Mustafa Nuri Elcioglu \\ Department of Ophthalmology, University of Health Sciences, Okmeydanı Traning and Research Hospital, Istanbul, Turkey
}

\begin{abstract}
Objectives: This study aims to compare the efficacy of intravitreal injection of aflibercept (IVA), ranibizumab (IVR) and dexamethasone implant (DEX IMP) for the treatment of macular edema (ME) secondary to branch retinal vein occlusion (BRVO). Methods: In this retrospective and comparative study, 57 eyes of 57 patients with ME after BRVO were studied. Patients were diveded into three groups according to treatment regimen as follows: $2 \mathrm{mg}$ IVA (group I, $\mathrm{n}=18$ ), $0,5 \mathrm{mg}$ IVR (group $2, n=20$ ) and 0,7 mg Dex imp (group 3, n= 19). Group I and group 2 were treated with three monthly anti-VEGF treatment followed by pro re nata (PRN) regimen, and group 3 was treated with 0,7 $\mathrm{mg}$ dexamethasone dose followed by another injection based on patients' data. Best-corrected visual acuity (BCVA), central macular thickness (CMT), intraocular pressure (IOP) measurements were noted at baseline, I, 2, 3 and 6 months.

Results: All groups were similar concerning age, gender, duration of symptoms, initial CMT and BCVA ( $>>0.05)$. Mean number of injections were $3,85 \pm 0.74$ in group $I, 3,85 \pm 0,87$ in group 2 and $1,75 \pm 0,44$ in group 3 . All the groups decreased CMT and increased BCVA for six months. There was not a statistically significant difference between groups. Concerning side effects, one person in group I and 2, four people in group 3 increased IOP, but all of them controlled IOP with antiglaucomatous drugs. One patient in group I, two in group 2, four in group three patients had cataract progression.

Conclusion: All three drugs have similar results in patients with ME secondary to BRVO at a six-month follow-up. Compared to anti-VEGF drugs, dex imp has side effects as increased IOP and cataract progression, but it has higher BCVA at all months in the treatment of ME after BRVO.
\end{abstract}

Keywords: Aflibercept, branch retinal vein occlusion, dexamethasone, macular edema, ranibizumab.

\section{Introduction}

Retinal vein occlusion (RVO) is the second most frequent retinal vascular disorder after diabetic retinopathy. RVO is divided into central retinal vein occlusion (CRVO) and branch retinal vein occlusion (BRVO). Vascular compression during arteriovenous passages, degenerative changes in venous walls and hypercoagulability are the underlying patho- physiology of BRVO. These factors increase the amount of vascular endothelial growth factor, which may increase vascular permeability and cause macular edema $(I, 2)$. Macular edema is the main cause of vision loss (3-8). There are some treatment modalities for macular edema, such as intravitreal dexamethasone implants, laser treatment, and intravitreal injections of anti-vascular endothelial growth factor (antiVEGF) agents (9-II). 
Corticosteroids are being used as a treatment option for ME. In recent years, intravitreal dexamethasone implantation (dex imp) was approved in patients with ME secondary to BRVO (I2). Other treatment options are anti-VEGF drugs: ranibizumab and aflibercept. Ranibizumab, which is an antiVEGF agent, was approved for the treatment of ME due to BRVO and CRVO in the United States, based on the BRAVO study $(13,14)$. After ranibizumab, another anti-VEGF aflibercept was approved for the treatment of ME after BRVO based on the VIBRANT study (I5). These treatment options have therapeutic and side effects. Despite these effects, there are not many studies about the comparison of these three drugs. Thus, we aimed to compare the efficacy and safety of intravitreal injection of aflibercept, ranibizumab and dexamethasone implant in the treatment of ME secondary to BRVO in this study.

\section{Methods}

In this study, 57 eyes of 57 patients were studied with treatment-naive ME after BRVO. Patients with CMT>300 in OCT were treated. Patients were divided into three different groups according to the treatment regimen. Group I $(n=18)$ was treated with $2 \mathrm{mg}$ IVA followed by PRN dosing. Group $2(n=20)$ was treated with $0.5 \mathrm{mg}$ IVR treatment followed by PRN dosing. Group $3(n=19)$ was treated with Dex imp, followed by another implant based on patients' clinical data. Patients $>18$ years old, with ME due to BRVO without ischemia or grid laser were included in this study. Patients with a history of cerebral infarction, vitrectomy, uveitis, glaucoma, or other vitreoretinal diseases were excluded from this study. All the patients had six months of followed-up time. None of the patients had ischemia on angiography or grid laser photocoagulation.

All intravitreal injections were performed under aseptic conditions in the operating room. Following the injection, a topical antibiotic drop was administered. No complication was seen during the injection.

All the patients had standard ophthalmic examinations at baseline, third and sixth month. The examinations included slit-lamp microscopy, BCVA, tonometry, SD-OCT and indirect ophthalmoscopy. The BCVA was measured with a Snellen chart, and the decimal visual acuity was converted to the logarithm of the minimal angle of resolution (logMAR) units for the statistical analyses. The OCT acquisition was performed on the SD-OCT (Cirrus HD-OCT; Carl Zeiss Meditec).

This retrospective study was conducted in accordance with the Declaration of Helsinki. All necessary authorizations were obtained from the Institutional Review Board of Okmeydanı Research\&Traning Hospital, İstanbul, Turkey, on 24/07/2018 with the number of 948 .

Statistical analyses were performed using the SPSS software version 2I. Descriptive analyses were presented using means and standard deviations for normally distributed variables. When investigating the changes in BCVA and CMT by time, repeated measures of analysis of variance test (ANOVA) were used. A $p<0.05$ value was accepted statistically significant.

\section{Results}

In this retrospective cohort study, 57 eyes of patients with ME secondary to BRVO were examined. All of the patients have a least six months follow-up time. We divided patients into three different groups according to their treatment regimen. Group I; had 18 eyes, which were treated with three monthly IVA followed by the PRN regimen. Group 2; also had 20 eyes, which were treated with three monthly IVR followed by PRN regimen. Group 3; had 19 eyes, which were treated dex imp and it was followed by another implantation if needed in six months. All the groups were similar concerning gender, age, duration of symptoms, initial CMT and BCVA $(p>0.05)$. The baseline characteristics of the patients were shown in Table I.

Table I. The baseline characteristics of the patients

\begin{tabular}{lcccc} 
& $\begin{array}{c}\text { Group I } \\
(\mathbf{n = 1 8})\end{array}$ & $\begin{array}{c}\text { Group 2 } \\
(\mathbf{n = 2 0})\end{array}$ & $\begin{array}{c}\text { Group 3 } \\
(\mathbf{n = 1 9 )}\end{array}$ & P \\
\hline Age (years) & $61.39 \pm 9.36$ & $61.25 \pm 10.30$ & $56.16 \pm 10.26$ & 0.109 \\
Gender (female/male) & $7 / 11$ & $8 / 12$ & $9 / 10$ & 0.397 \\
Duration of the symptoms (days) & $27.2 \pm 10.3$ & $25.4 \pm 8.1$ & $28.1 \pm 7.3$ & \\
Initial CMT ( $\mu$ m) & $476 \pm 152$ & $524 \pm 162$ & $500 \pm 93$ & 0.568 \\
Initial BCVA (logMAR) & $1.00 \pm 0.58$ & $0.87 \pm 0.58$ & $0.91 \pm 0.48$ & 0.710 \\
Phakic/Pseudophakic & $14 / 4$ & $17 / 3$ & $16 / 3$ & \\
Mean follow-up time & $8.6 \pm 1.9$ & $9 \pm 2$ & $8.4 \pm 1.7$ & 0.703
\end{tabular}




\section{Anatomical Results}

At baseline, CMT was $476.83 \pm 152.38 \mu \mathrm{m}$ in group-I, $524.60 \pm 162.94 \mu \mathrm{m}$ in group-2.500 $\pm 93.45 \mu \mathrm{m}$ in group-3. After three monthly anti-VEGF injections and one dex imp, the patients were examined at the I, 2, 3 and 6 months. Group-I has $293 \pm 66 \mu \mathrm{m}, 273 \pm 47 \mu \mathrm{m}, 28 \mathrm{I} \pm 44 \mu \mathrm{m}, 268 \pm 28$ $\mu \mathrm{m}$, group -2 has $377 \pm 101 \mu \mathrm{m}, 295 \pm 56 \mu \mathrm{m}, 278 \pm 105 \mu \mathrm{m}$, $276 \pm 88 \mu \mathrm{m}$, and group -3 has $325 \pm 33 \mu \mathrm{m}, 280 \pm 36 \mu \mathrm{m}$, $266 \pm 56 \mu \mathrm{m}, 253 \pm 45 \mu \mathrm{m}$ at I, 2, 3 and 6 months respectively. There was not a statistically significant difference between groups (Table 2). The CMT overtime was displayed in Figure I.

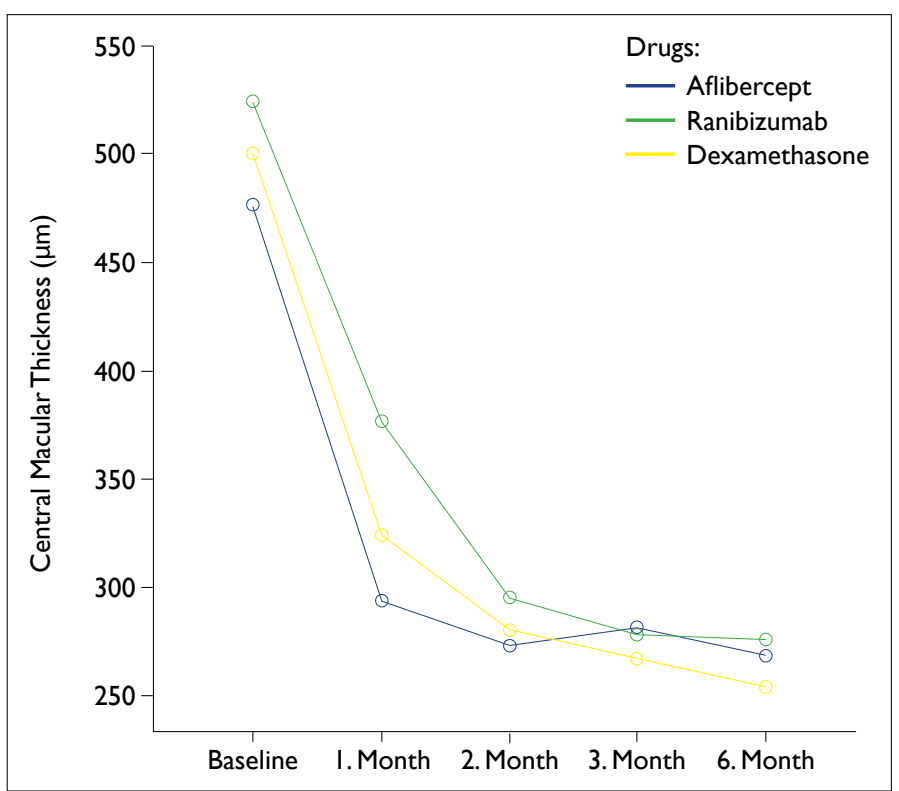

Figure I. CMT overtime.

Table 2. Changes in CMT, BCVA and side effects of the treatments

Table 2. Chanes in CMTBCVA and side effets of the treatnents

\begin{tabular}{|c|c|c|c|c|}
\hline & Group I & Group 2 & Group 3 & $\mathbf{p}$ \\
\hline Ist month CMT $(\mu \mathrm{m})$ & $293 \pm 66$ & $377 \pm 101$ & $325 \pm 33$ & 0.001 \\
\hline I $^{\text {st }}$ month BCVA (logMAR) & $0.73 \pm 0.81$ & $0.67 \pm 0.54$ & $0.53 \pm 0.30$ & 0.804 \\
\hline $2^{\text {nd }}$ month $C M T(\mu \mathrm{m})$ & $273 \pm 7$ & $295 \pm 56$ & $280 \pm 36$ & 0.571 \\
\hline $2^{\text {nd }}$ month $B C V A(\log M A R)$ & $0.60 \pm 0.61$ & $0.49 \pm 0.53$ & $0.35 \pm 0.32$ & 0.573 \\
\hline $3^{\text {rd }}$ month CMT $(\mu \mathrm{m})$ & $273 \pm 47$ & $278 \pm 105$ & $266 \pm 56$ & 0.149 \\
\hline $3^{\text {rd }}$ month BCVA (logMAR) & $0.46 \pm 0.43$ & $0.40 \pm 0.57$ & $0.3 \mid \pm 0.31$ & 0.680 \\
\hline $6^{\text {th }}$ month $\mathrm{CMT}(\mu \mathrm{m})$ & $268 \pm 28$ & $276 \pm 88$ & $253 \pm 45$ & 0.258 \\
\hline $6^{\text {th }}$ month BCVA (logMAR) & $0.39 \pm 0.42$ & $0.39 \pm 0.54$ & $0.30 \pm 0.28$ & 0.991 \\
\hline Number of injections & $3.78 \pm 0.73$ & $3.85 \pm 0.87$ & $1.74 \pm 0.45$ & 0.000 \\
\hline Cataract progression, (\%) & $1 / 14(7.14)$ & $2 / 17(11.76)$ & $4 / 16(25)$ & \\
\hline Usage of anti-glaucomatous, (\%) & I/18 (5.55) & $\mathrm{I} / 20(5)$ & $4 / 19(21.05)$ & \\
\hline
\end{tabular}

CMT; central macular thickness; BCVA; best-corrected visual acuity. 
glaucomatous drop. Also, one person in group-I, two people in group-2, four people in group-3 had cataract progression.

\section{Discussion}

In our study, we aimed to compare three different treatment options, aflibercept, ranibizumab and dexamethasone in the treatment of ME after BRVO in real-life data. If we look separately, all drugs were successful in anatomical and visual gain. Even if it was not statistically significant, dexamethasone implantation had the best visual acuity at all times. However, after dexamethasone implantation $2 \%$ patients ( 4 eyes) increased IOP, while this percentage was $5 \%$ in groups I and 2 . For a long time, argon laser photocoagulation has been used in BRVO and has been recommended as a treatment method for reducing $M E$ and increasing visual acuity $(16,17)$. In recent years, several studies showed that vascular endothelial growth factor and inflammatory mediators like interleukin-6 were increased in ME after BRVO $(18,19)$. After this discovery, anti-VEGF drugs and corticosteroids were considered as a treatment option in ME after BRVO.

Dexamethasone implantation (Ozurdex; Allergan, Inc., Irvine, CA, USA) was approved in ME due to BRVO after multicenter, randomized, sham-controlled trial of GENEVA.I2 Several studies in diabetic macular edema showed that the effects of dex imp continued three or four months after that additional implantation is required $(20,21)$. Bandello et al. suggested that dex imp was successful in ME after BRVO. However, they said that to maintain this benefit, the interval between retreatment must be lower than six months (22). With this thought, we performed additional implantation three or four months later if needed. In a study, Kaldırım et al. compared the different treatment options similar to our study. However, they performed only a single dose dex imp, because of that, they found dex imp group had higher CMT and lowered BCVA at month six (23). Unlike them, we found that dex imp group has lower CMT and higher BCVA at month six. In a recent study, Sibylle et al. compared dexamethasone and ranibizumab in BRVO and CRVO patients (24). Similar to our study, they performed additional dex imp based on clinical data. They found dex imp was comparable to ranibizumab in 1.13 mean number of injections in BRVO. Aflibercept, which is a recombinant fusion protein consisting of VEGF-binding receptors I and 2 fused to the Fc portion of the human immunoglobulin, was approved after multicenter randomized VIBRANT trial (I5). They compared aflibercept to laser photocoagulation. Aflibercept was successful in the management of ME with a mean number of 5.7 injections in VIBRANT study. Similar to VIBRANT study, we found that aflibercept provided visual and anatomical gain at month six. The mean number of injections was fewer than VIBRANT study $(3.78 \pm 0.73$ in our study, 5.7 in the VIBRANT study). No systemic side effects were discov- ered in our study. One patient had cataract progression, and one patient increased IOP with IVA injections. In a real-life study, Ozkaya et al. (25) studied BRVO and CRVO patients, which were either naive or persistent ME previously treated with ranibizumab. In that study, aflibercept was found to be effective in naive and persistent ME after BRVO.

Ranibizumab is a humanized monoclonal antibody fragment that binds VEGF. It was approved after a multicenter, randomized, sham-controlled BRAVO trial (I3). In the BRAVO study, ranibizumab was compared sham injections and found successful concerning anatomical and visual gain with a mean number of 5.7 injections. We found that ranibizumab has provided visual and anatomical gain at month six with mean number of $3.85 \pm 0.87$ injections.

In our study, aflibercept and ranibizumab had similar results. Both anti-VEGF drugs managed to gain visual recovery and they had similar injections number $(3.78 \pm 0.73$ and $3.85 \pm 0.87$, respectively). In a "treat and monitor" study, Puchi et al. (26) demonstrated that aflibercept and ranibizumab may show similar results at month twelve. They did not perform three monthly injections, and they performed on initial IVA or IVR injections. After that, patients were subsequently followed up every four weeks. The decision to retreatment was taken by the investigator on the basis of the CMT change, and the report submitted separately by the BCVA examiner. Despite that, they demonstrated that ranibizumab and aflibercept may have similar results concerning treat and monitor regimen.

There are some limitations to our study. First, this is a retrospective study. Second, we do not have fourth or fifth months data.

In conclusion, all treatment modalities have shown similar results in our study. Although four eyes had cataract progression in the dex imp group, BCVA was better than IVR and IVA groups at all time, and the Dex imp group had a fewer number of injections. We thought that if all eyes were pseudophakic, BCVA could be higher and statistically significant in the dex imp group. In addition, dex imp may be considered a more useful option if we consider the finances of the patients because of multiple injections.

\section{Disclosures}

Ethics Committee Approval: All necessary authorizations were obtained from the Institutional Review Board of Okmeydanı Research and Traning Hospital, İstanbul, Turkey with number of 948 at 24.7.2018.

Peer-review: Externally peer-reviewed.

Conflict of Interest: None declared.

Authorship Contributions: Involved in design and conduct of the study (AHB, SB, ME); preparation and review of the study (AHB, BE, AC, ME); data collection (AHB, MT, SGO); and statistical analysis (AC, $B E, S B)$. 


\section{References}

I. Jaulim A, Ahmed B, Khanam T, Chatziralli IP. Branch retinal vein occlusion: epidemiology, pathogenesis, risk factors, clinical features, diagnosis, and complications. An update of the literature. Retina 2013;33:901-10. [CrossRef]

2. Son BK, Kwak HW, Kim ES, Yu SY. Comparison of Ranibizumab and Bevacizumab for Macular Edema Associated with Branch Retinal Vein Occlusion. Korean J Ophthalmol 2017;31:209-16.

3. Cruz N, Pinilla I, Casas P, Garcia-Martin E, Idoipe M, Fuertes I. Ranibizumab for macular edema following branch retinal vein occlusion. Acta Ophthalmologica 2010;88.0. [CrossRef]

4. Moon BG, Cho AR, Kim YN, Kim JG. Predictors of Refractory Macular Edema After Branch Retinal Vein Occlusion Following Intravitreal Bevacizumab. Retina 2018;38:I 166-74. [CrossRef]

5. Hayreh SS, Podhajsky PA, Zimmerman MB. Branch retinal artery occlusion: natural history of visual outcome. Ophthalmology 2009; I 16: I 188-94. [CrossRef]

6. Hayreh SS. Ocular vascular occlusive disorders: natural history of visual outcome. Prog Retin Eye Res 2014;41:1-25. [CrossRef]

7. Rogers SL, Mclntosh RL, Lim L, Mitchell P, Cheung N, Kowalski JW, et al. Natural history of branch retinal vein occlusion: an evidence-based systematic review. Ophthalmology 2010; I 17:1094-101. [CrossRef]

8. Wong TY, Scott IU. Clinical practice. Retinal-vein occlusion. N Engl J Med 2010;363:2135-44. [CrossRef]

9. Mylonas G, Sacu S, Dunavoelgyi R, Matt G, Blum R, Buehl W, et al; Macula Study Group. Response of retinal sensitivity to ranibizumab treatment of macular edema after acute branch retinal vein occlusion. Retina 2013;33:1220-6. [CrossRef]

10. Korobelnik JF, Kodjikian L, Delcourt C, Gualino V, Leaback R, Pinchinat $S$, et al. Two-year, prospective, multicenter study of the use of dexamethasone intravitreal implant for treatment of macular edema secondary to retinal vein occlusion in the clinical setting in France. Graefes Arch Clin Exp Ophthalmol 2016;254:2307-18. [CrossRef]

I I. Kamei M, Terasaki H, Yoshimura N, Shiraga F, Ogura Y, Grotzfeld AS, et al. Short-term efficacy and safety of ranibizumab for macular oedema secondary to retinal vein occlusion in Japanese patients. Acta Ophthalmol 2017;95:e29-e35. [CrossRef]

12. Haller JA, Bandello F, Belfort R Jr, Blumenkranz MS, Gillies M, Heier J, et al; Ozurdex GENEVA Study Group. Dexamethasone intravitreal implant in patients with macular edema related to branch or central retinal vein occlusion twelve-month study results. Ophthalmology 20 I I; I 18:2453-60. [CrossRef]

13. Campochiaro PA, Heier JS, Feiner L, Gray S, Saroj N, Rundle AC, et al; BRAVO Investigators. Ranibizumab for macular edema following branch retinal vein occlusion: six-month primary end point results of a phase III study. Ophthalmology 2010; I17:1 102-12. [CrossRef]

14. Campochiaro PA, Brown DM, Awh CC, Lee SY, Gray S, Saroj
$N$, et al. Sustained benefits from ranibizumab for macular edema following central retinal vein occlusion: twelve-month outcomes of a phase III study. Ophthalmology 20 I I; I 8:204 I9. [CrossRef]

15. Campochiaro PA, Clark WL, Boyer DS, Heier JS, Brown DM, Vitti R, et al. Intravitreal aflibercept for macular edema following branch retinal vein occlusion: the 24-week results of the VIBRANT study. Ophthalmology 2015;122:538-44. [CrossRef]

16. The Branch Vein Occlusion Study Group. Argon laser photocoagulation for macular edema in branch vein occlusion. The Branch Vein Occlusion Study Group. Am J Ophthalmol 1984;98:27I-82. [CrossRef]

17. Battaglia Parodi M, Saviano S, Ravalico G. Grid laser treatment in macular branch retinal vein occlusion. Graefes Arch Clin Exp Ophthalmol 1999;237:1024-7. [CrossRef]

18. Noma H, Funatsu H, Yamasaki M, Tsukamoto H, Mimura T, Sone $\mathrm{T}$, et al. Aqueous humour levels of cytokines are correlated to vitreous levels and severity of macular oedema in branch retinal vein occlusion. Eye (Lond) 2008;22:42-8. [CrossRef]

19. Noma H, Funatsu H, Mimura T, Harino S, Hori S. Vitreous levels of interleukin-6 and vascular endothelial growth factor in macular edema with central retinal vein occlusion. Ophthalmology 2009; I 16:87-93. [CrossRef]

20. Scaramuzzi M, Querques G, Spina CL, Lattanzio R, Bandello F. Repeated intravitreal dexamethasone implant (Ozurdex) for diabetic macular edema. Retina 2015;35:1216-22. [CrossRef]

21. Panozzo G, Gusson E, Panozzo G, Dalla Mura G. Dexamethasone intravitreal implant for diabetic macular edema: indications for a PRN regimen of treatment. Eur J Ophthalmol 20I5;25:347-5I. [CrossRef]

22. Bandello F, Parravano M, Cavallero E, Cascavilla ML, Triolo G, Querques L, et al. Prospective evaluation of morphological and functional changes after repeated intravitreal dexamethasone implant (Ozurdex®) for retinal vein occlusion. Ophthalmic Res 20I5;53:207-16. [CrossRef]

23. Kaldırım HE, Yazgan S. A comparison of three different intravitreal treatment modalities of macular edema due to branch retinal vein occlusion. Int Ophthalmol 2018;38:1549-58. [CrossRef]

24. Winterhalter S, Eckert A, Vom Brocke GA, Schneider A, Pohlmann D, Pilger D, et al. Real-life clinical data for dexamethasone and ranibizumab in the treatment of branch or central retinal vein occlusion over a period of six months. Graefes Arch Clin Exp Ophthalmol 2018;256:267-79. [CrossRef]

25. Ozkaya A, Tulu B, Garip R. Aflibercept in macular edema secondary to retinal vein occlusion: A real life study. Saudi J Ophthalmol 2017;31:2। I-5. [CrossRef]

26. Pichi F, Elbarky AM, Elhamaky TR. Outcome of "treat and monitor" regimen of aflibercept and ranibizumab in macular edema secondary to non-ischemic branch retinal vein occlusion. Int Ophthalmol 2019;39:145-53. [CrossRef] 